\title{
A imaginação na Carta sobre os cegos, ou o órgão do bon sens
}

Imagination in Diderot's Lettre sur les aveugles

or, the organ of bons sens

\section{Luís Fernandes dos Santos Nascimento \\ Universidade Federal de São Carlos}

RESUMO

O presente texto busca compreender a relação entre as noções de bom senso e imaginação, tal como se apresentam na Carta sobre os cegos de Denis Diderot.

\section{PALAVRAS-CHAVE}

Diderot, Imaginação, Bom senso, Cegueira.

\begin{abstract}
The aim of the article is to comprehend the relation between the notions of good sense and imagination in Diderot's Lettre sur les aveugles.
\end{abstract}

\section{KEY WORDS}

Diderot, Imagination, Good Sense, Blindness. 


\section{O que é a imaginação de um cego? É um fenômeno mais dificil de explicar do que parece.}

Diderot (1915b, p. 870)

Célebre por ter proporcionado a Diderot um período de aprisionamento no Château de Vincennes, a Carta sobre os cegos para o uso dos que veem (I749) é, como diz Yvon Belaval, "uma conversa que narra outras conversas" (Belaval 2003, p. 152). Vale lembrar, como o faz Franklin de Matos, que o gênero epistolar para Diderot é "um lugar apropriado para se conversar livremente" (Franklin de Matos 200I, p. 147). A carta é um dos meios mais eficazes de expressar o curso de um diálogo e da sociabilidade que deve reinar entre os interlocutores que, com liberdade, trocam e comunicam suas ideias e opiniōes acerca de um ou de vários assuntos. No caso específico da Carta sobre os cegos, teríamos uma primeira e grande conversa com aquela a quem a epístola se dirigiria, a saber: Madame de Puisieux, personagem que não é nomeada no corpo do texto, mas que os editores tendem a identificar como sendo sua provável destinatária. O que sabemos é que Diderot, ou antes, o autor da Carta, endereça-se a uma mulher interessada por uma questão que, desde que Molyneux a propôs a Locke e que este a incorporou em seu Ensaio sobre $o$ entendimento humano, vem despertando a atenção de sábios e filósofos, a saber: se um cego de nascença, quando operado e restituído de sua visão, poderia ou não ser capaz de distinguir pelos olhos figuras que ele até então conhecia apenas pelo tato, tais como um cilindro ou um cubo.

No interior desta que seria a sua maior e principal conversa (que é a que se estabelece com aquela a quem ele se dirigiria: Madame de Puisieux), o texto nos apresenta duas outras que lhe servirão de exemplo e de argumento para o modo como aqui se pensa a questão que tem em Molyneux a sua origem. A primeira dessas conversas é com o chamado cego de Puisaux, com quem o autor da Carta teria se encontrado e travado um diálogo. A segunda tomaria de empréstimo uma conversa que o cego, matemático e eminente membro da Royal Society, Nicholas Saunderson, teria tido em seu leito de morte com o seu confessor, Mr. Holmes. A fonte dessa conversa seriam as biografias escritas sobre Saunderson, mas muito do que então é dito, adverte-nos André Billy em nota à sua edição da Carta, seria mais invenção de Diderot do que palavras que o próprio matemático teria proferido antes de morrer. O filósofo francês chega mesmo a indicar à sua interlocutora (Madame de Puisieaux) e "a todos que entendem um pouco o inglês" (Diderot 1979, p. 20) aquela que ele considera como sendo a melhor das biografias feitas acerca do matemático cego, escrita por um certo William Inchlif e publicada em I747, em Dublin. Tal autor, bem como sua obra, jamais existiu e é, como afirma 
a edição brasileira da Carta, "pura invenção de Diderot" (Diderot 1979, p. 20). Independentemente de serem informaçôes inverídicas e de não corresponderem ao que poderíamos aqui chamar de verdade histórica, o certo é que o recurso a essas "invenções" dá a Diderot a possibilidade de apresentar a questão proposta por Molyneux sob uma nova luz, muito distinta daquela como fora apresentada por Locke, por exemplo.

Já nas primeiras linhas, a primeira das conversas relatadas (a que tem o cego de Puisaux como interlocutor), o tema já é considerado sob uma nova perspectiva: não é mais o caso de se investigar o cego recentemente operado, no momento em que ele começa a ver, mas antes de tudo entender o universo que o não vidente percebe. Antes de mais nada, trata-se de dar voz ao cego e de compreender as complexidades do mundo no qual ele vive. Como resultado dessa operação, baseada na simples ideia de deixar o cego falar, o texto desvenda outra realidade ou outra maneira de viver e de se relacionar não só com os sentidos, mas também com as faculdades intelectivas. Não são poucos os exemplos fornecidos pela Carta que nos servem para relativizar ideias ou opinióes que tomamos como certas, como verdadeiras ou mesmo como sendo as mais comuns ou costumeiras:

Chegamos à casa de nosso cego por volta das cinco horas da tarde, e encontramo-lo ocupado em fazer o filho ler com caracteres em relevo: não havia mais de uma hora que se levantara; pois deveis saber que o dia começa para ele quando termina para nós. Seu costume é dedicar-se a seus negócios domésticos, e trabalhar enquanto os outros dormem. (Ibid., pp. 3-4)

Como o trecho acima deixa claro, o cego acorda e dorme em um horário que não o mesmo daqueles dos videntes, ele trabalha e vive numa ordem distinta da nossa. Sua estrutura física, o fato de ter um sentindo a menos, o faz perceber um universo que lhe é peculiar, assim como também o faz desenvolver certas habilidades que nos parecem surpreendentes: "ele tem a memória dos sons em grau surpreendente; e os rostos não nos oferecem diversidade maior do que a que ele observa nas vozes". (Ibid., p. 6)

No cego, a privação de um órgão faz então com que os outros que lhe restam se desenvolvam de tal maneira que Diderot pode mesmo dizer que eles chegam a substituir a visão, ao ponto de afirmar que Saunderson vê pelo tato. Este órgão em especial parece ser aquele que mais se aperfeiçoa no cego e toda a linguagem que o grande sábio britânico desenvolve, bem como os aparelhos que construiu para os estudos que fez de matemática, de física e de geometria, têm no tato o seu maior alicerce: "o exemplo do ilustre cego prova que o tato pode tornar-se mais delicado que a vista, quando aperfeiçoado pelo exercício”. (Diderot 1979, p. I7) 
O mesmo fenômeno pode ser observado no cego de Puisaux, que — tal como Saunderson - possui um apurado sentido do tato, assim como o da audição: "o polido dos corpos quase não oferece menos matizes ao nosso cego do que o som da voz, e ele não precisaria ter medo de tomar sua mulher por outra, a menos que ganhasse na troca." (Ibid., p. 7)

Todos esses exemplos estão apoiados em uma ideia defendida pela Carta, segundo a qual existe uma estreita relação, e mesmo continuidade, entre os dados e sensações que nos são oferecidos pelos nossos sentidos e as noções e conhecimentos que, a partir deles, formamos. Tão logo começamos a sentir, começamos também a pensar e a própria natureza de nossas faculdades, no momento mesmo em que passam a atuar, nos levaria a conceber nossas primeiras noções, como as

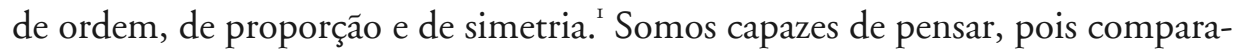
mos os diversos e múltiplos dados que os sentidos nos fornecem e fazemos isso ao mesmo tempo em que sentimos. Desse ponto de vista, sentir não é atividade distinta da de estabelecer relaçôes (rapports, nos termos empregados por Diderot no verbete Belo da Enciclopédia) a partir de elementos perceptivos. Ideias, noções abstratas ou conhecimentos não são senão frutos de uma única e mesma atividade que é sentir e pensar. Sob esse aspecto, não posso sentir sem também pensar, isto é: sem comparar as diversas percepções que tenho e posso ter, sem estabelecer entre elas relações e proporções. As noções abstratas e gerais às quais podemos chegar não seriam então senão algo como uma sensação de segunda potência, e a reflexão e a abstração não poderiam mais ser entendidas como qualitativamente diversas da percepção - se há uma diferença entre o que sentimos e o que pensamos, trata-se antes de uma distinção de grau. Pensar bem não poderá então ser algo diferente de sentir bem, o que equivaleria dizer que aperfeiçoar os sentidos é desenvolver o pensamento.

Por essa razão, quando temos de levar em conta que existem indivíduos que, por conta de uma compleição peculiar, como os cegos, sentem diferentemente da maioria dos homens, então também teremos de considerar que seus modos de pensar e conceber as coisas são, e têm de ser, distintos dos nossos. Nos termos da Carta:

Como jamais duvidei de que o estado de nossos órgãos e de nossos sentidos tem muita influência sobre nossa metafísica e sobre nossa moral, e que nossas ideias mais puramente intelectuais, se posso assim exprimir-me, dependem muito de perto da conformação de nosso cor-

I A esse respeito, ver o verbete Belo da Enciclopédia. (Diderot 20I5) 
po, comecei a questionar nosso cego acerca dos vícios e das virtudes.

(Diderot 1979, p. 8)

Como vimos, todo o mundo do cego é dependente de sua compleição e estrutura física, toda a atividade que é a de seu pensamento está intimamente ligada ao modo como ele sente as coisas. Por isso, não é de admirar que suas noções e ideias sejam diferentes das que temos. "Quantos princípios existem para eles, que não passam de absurdos para nós e reciprocamente”, diz a Carta. (Ibid., p. 8) A moral e a metafísica dos cegos portam a peculiaridade do modo como percebem o universo que os rodeia, assim como ocorre conosco. E então nada seria mais evidente do que pensar que, "em um povo de cegos" (Ibid., p. 6), as leis e o modo como a sociedade se organizaria corresponderiam à maneira como seus cidadãos sentem e pensam. Poderíamos imaginar que mesmo a linguagem que então se empregaria teria de ser moldada tendo em vista a compleição de seus habitantes, tal como acontece conosco, videntes. É curioso perceber, no interior mesmo da Carta, os limites da linguagem dos videntes: nossas palavras estão tão carregadas de elementos visuais que chega a ser difícil não dizer que os cegos veem, como ocorre no seguinte trecho: "como veem a matéria de maneira muito mais abstrata do que nós, encontram-se menos distantes de crer que ela pensa”. (Ibid., p. 8) Evidentemente (e "evidente" já é um desses termos que são de origem visual), o cego não vê e se o autor da Carta pode dizer isso, é porque emprega o verbo ver em um uso metafórico, como sinônimo de perceber - o que mostra que, para um vidente, como o autor da Carta, o sentido da visão é tão predominante em seu modo de sentir e pensar as coisas que ele passa a valer como perceber, e muitas vezes em que dizemos ver estamos querendo unicamente dizer perceber. O mesmo deve ocorrer em relação ao cego tendo em vista (com o perdão da expressão) a predominância que o tato, segundo a Carta, tem em sua maneira de perceber. Teríamos então uma linguagem predominantemente táctil no lugar de uma visual, em que pegar e tocar poderiam ser entendidos como sinônimos de perceber.

Não é então de surpreender que a noção que os cegos têm de beleza tenha no tato o seu fundamento e que, ao contrário de nós, não leve em consideração elementos visuais, como o faz o cego de Puisaux. Se essa última afirmação nos parece óbvia, as consequências que a Carta retira de tais consideraçôes não parecerão tão simples quando levamos em conta algumas de nossas mais caras crenças. Porque é cego, porque pensa e sente como cego, o sábio Saunderson não pode aceitar os argumentos que seu confessor, Mr. Holmes, emprega para persuadi-lo da existência de Deus. Em seu leito de morte, Saunderson rebate cada um dos raciocínios apresentados pelo ministro e quando Mr. Holmes invoca a ordenação 
e as belezas que se pode contemplar na natureza como sendo uma prova de seu criador, é raciocinando como cego que Saunderson responde: "ah, senhor, dizia-lhe o filósofo cego, deixai de lado todo esse belo espetáculo que nunca foi feito para mim! Fui condenado a passar minha vida nas trevas; e vós me citais prodígios que não entendo, e que só provam para vós e para os que veem como vós. Se quereis que eu creia em Deus, cumpre que me façais tocá-lo”. (Ibid., p. 18)

Todo o discurso do vidente não pode ser aceito pelo cego como uma verdade incontestável. Sua própria condição, sua maneira de pensar e sentir, já lhe são suficientes para relativizar o que para nós pode ser tido como certo. Aquilo que para nós é "evidência" pouco ou nada pode dizer ao cego. Percebemos que a figura do cego serve a Diderot para colocar em dúvida o que tomamos como verdade, bem como para investigar a fonte daquelas ideias ou crenças que tomamos como sendo verdadeiras e absolutas. Nesse sentido, recorrer ao exemplo do cego já é pressupor a possibilidade de que nossa estrutura física possa mudar e que, do mesmo modo, muito do que consideramos como sendo certo possa ser desacreditado.

Tudo parece então estar relativizado quando se considera as diversas possibilidades de sentir e, portanto, de pensar. $\mathrm{O}$ cego não é então outra coisa senão a figura das diferenças que se pode notar entre aqueles que sentem ou entre as diversas maneiras que temos de sentir. No limite, os cegos ou os surdos apenas explicitam uma diferença que é a de todos nós. Pois, se pensarmos bem, quem de nós tem uma compleição física idêntica ao do outro? Mesmo em meio a videntes, podemos considerar que cada qual vê ou percebe do seu modo particular e distinto. Podemos pensar que um primeiro sofre de certo grau de miopia que o diferencia de outros míopes, que um segundo tem determinado grau de astigmatismo, que um terceiro é daltônico e assim por diante. $\mathrm{O}$ mesmo em relação a todos os outros sentidos. Como nos mostra esta passagem do verbete Percepção da Encyclopédie (de autor desconhecido), a própria noção de percepção parece implicar essa ideia segundo a qual os modos de perceber mudam de acordo com a estrutura física daquele que percebe:

Tomai criaturas que sejam privadas da visão, outras que sejam privadas da visão e da audição e assim por diante, obtereis rapidamente criaturas que, sendo privadas de todos os sentidos, não receberão nenhum conhecimento. Suponde o contrário, se é possível, novos sentidos em homens mais perfeitos do que nós. Quantas novas percepçôes! Por consequência, quantos conhecimentos ao seu alcance, os quais não podemos atingir e sobre os quais não podemos sequer formar conjecturas! (Diderot \& d'Alembert I75I) 
Uma vez que se considera a relação íntima entre sentir e conhecer ou sentir e pensar, as infinitas possibilidades de compleição correspondem às inúmeras maneiras de se conhecer, como também lembra D’Alembert no verbete Cego da Enciclopédia, verbete que se apresenta como uma espécie de resenha da Carta de Diderot: "essa carta termina com algumas reflexôes sobre o que ocorreria a um homem que tivesse a visão desde seu nascimento e que não teria o sentido do toque, e sobre um homem cujos sentidos da visão e do toque se contradissessem perpetuamente." (d'Alembert I75I)

O grande pressuposto que as passagens acima citadas nos apresentam é aquele segundo o qual sem sentir não se conheceria, mas ao afirmar isso elas abrem infinitas possibilidades de considerar diversos modos de percepção. Podemos então pensar em várias possibilidades: seres destituídos de visão, seres destituídos de audição, seres com outros sentidos que desconhecemos etc. A cada uma dessas possibilidades um novo universo se abre: o mundo do cego, o mundo do surdo, o mundo do vidente, o mundo de um homem com sete ou oito sentidos etc. Estaríamos diante de universos distintos nos quais as verdades e crenças correspondem aos sentidos que os percebem. Mundos que se diferenciam e que se relativizam quando considerados a partir da peculiaridade dos sentidos que os percebem: diferentes códigos morais, diferentes metafísicas poderiam ser então vislumbradas. E quando lembramos que cada um de nós sente o mundo de acordo com nosso modo próprio de sentir, então teríamos uma quantidade de mundos tão grande quanto é a de seres que percebem. O que o exemplo dos cegos nos ensina é que mesmo entre nós videntes, as certezas podem ser relativizadas ao considerarmos que cada um de nós percebe de maneira diferente dos outros. Os homens veem e percebem de modos diversos. De acordo com nossas próprias maneiras de pensar e sentir, nos tornamos seres singulares, dotados de um traço distintivo ou caráter que nos é próprio. Cada um de nós é diferente dos demais. Se, como nos mostra a Satyre Première, o caráter dos homens tende a encontrar na escolha que fazem por certa profissão uma manifestação a partir da qual podemos compreender algo de suas características pessoais, então a consideração das diversas atividades ou ocupações que desempenhamos também poderia nos revelar diferentes olhares, diferentes pontos de vistas fundados em modos particulares de perceber. É o que nos indica uma anedota relatada nesta Satyre première. Diderot está em um concerto de música, ao seu lado o "naturalista Daubenton", no palco canta Caffarelli. Termina a exibição, todos parecem admirados, Diderot se dirige ao amigo: "E então, doutor, que dizeis disso?". No lugar de ouvir elogios à voz do cantor, Diderot escuta uma série de descrições acerca da compleição de Caffarelli: suas pernas eram finas, o quadril largo, as coxas grossas, nenhum pelo no queixo, 
uma voz de mulher e, diz-nos Diderot, enquanto o cantor levava o público às lágrimas, Daubenton "l'examinait en naturaliste". (Diderot I994, pp. 587-588)

Daubenton vê de acordo com sua maneira de conceber as coisas: o mundo que ele percebe não é exatamente o mesmo daquele do autor da Satyre première: ele vê como um naturalista, assim como Saunderson vê como matemático e cego. O mesmo objeto (le castrat Caffarelli, no caso) pôde ser tomado de maneiras tão distintas que já nem mais parece ser o mesmo objeto. Voltamos então à constatação segundo a qual, no limite, a distância que nos separa dos cegos não é tão distinta daquela que existe entre nós e todos os outros homens, videntes ou não: ao examinarmos com minúcia as distintas formas físicas, a diversidade de opiniōes, de costumes, de escolhas e de caracteres que nos separam, chegamos à conclusão de que a quantidade de mundos, verdades e realidades possíveis é tão grande quanto as possibilidades de conceber diferentes modos de perceber. E é aqui que a Carta apresenta algo de extrema importância. Malgrado todas as peculiaridades que separam nosso mundo do universo dos cegos, eles ainda se comunicam conosco. Eis aí o que o cego de Puisaux diz àqueles que se surpreendem com seus feitos e com sua habilidade e aptidão para um grande número de coisas: "percebo bem, senhores, nos disse ele, que não sois cegos; estais surpresos com o que faço; e por que não vos espantais também pelo fato de que falo?” (Diderot 1979, p. 7)

A grande questão é: o cego fala, ele nos diz algo que faz sentido. Apesar de todas as diferenças que nos separam do universo que habitam, o cego de Puisaux e Saunderson se comunicam, e suas ideias e pensamento fazem sentido para nós, videntes. A questão que se põe já não é mais exatamente a de saber a distância que se pode estabelecer entre cegos e videntes ou entre surdos e cegos ou entre videntes com diferentes graus de visão, com diferentes aptidões ou distintos caracteres. $\mathrm{O}$ ponto ao qual a Carta nos conduz é aquele que considera a possibilidade de uma comunicação. Por certo, considera-se o fato de que cada homem, naquilo que o faz particular, se distingue dos demais, mas que ainda assim seria possível conceber um lugar, ocasião ou momento em que, apesar de todas as diferenças, todos eles poderiam entrar em contato. Afinal, entendemos o discurso do cego, assim como entendermos o do naturalista. Essa seria a grande questão que o problema dos cegos nos levaria a considerar, um tema que iria muito além da formulação que Molyneux lhe conferiu: "procurou-se restituir a vista a cegos de nascença; mas se se olhasse o fato mais de perto, verificar-se-ia, creio, que se pode realmente aproveitar outro tanto para filosofia questionando um cego de bom senso (bon sens)". (Diderot I979, p. 2I)

Encontramos aqui o ponto que realmente importa: para além das diferenças perceptivas e modos de perceber, o bon sens é o que deve imperar. De nada vale questionar um cego que recentemente passou a ver, pois a ele ainda não foi dado 
o tempo para refletir e pensar acerca dos dados que seu novo sentido lhe oferece. Os sentidos precisam ser aperfeiçoados, eles precisam se tornar um bon sens. É justamente isso que não falta nem ao cego de Puisaux, nem a Saunderson e a questão já não é mais a de saber quantos sentidos eles têm ou de quantos eles foram privados, até porque já podemos pensar que pode existir homens com mais de cinco sentidos, e sim a de saber se eles, não obstante o fato de carecerem de um dos sentidos, são ainda homens de bon sens. Disso, a Carta não parece ter dúvida e já no seu início nos dirá que o cego de Puisaux "é um homem que não carece de bom senso" (Diderot I979, pp. 818-882) e o mesmo não se pode negar a Saunderson. A marca desse bon sens parece ser dada na própria coerência que se percebe no discurso e no modo como o cego de Puisaux e Saunderson elaboram e transmitem suas ideias. Se, podemos perguntar, o termo bon sens designa algo como um aperfeiçoamento dos sentidos, mas que é ainda (ele mesmo) um sens, tal como o são a visão e a audição, qual seria o seu órgão? Existiria para o bon sens algo como o que é o olho para a visão ou o ouvido para a audição? Em outras palavras: de que atividade dependeria esse sentido que confere ordem e mesmo sentido (significado, se assim podemos dizer) aos demais? Ao levar em consideração o texto da Carta, tudo leva a crer que se este órgão não é a imaginação, ele estaria ligado a ela.

Termo complexo e de difícil definição, a imaginação aparece no interior da Carta como sendo algo do qual os cegos estariam - em um primeiro momento — privados: "ele (o cego) não imagina; pois, para imaginar, é preciso colorir um fundo e destacar este fundo dos pontos, atribuindo-se-lhes uma cor diferente da do fundo" (Diderot 1979, p. 9). Imaginação é então aqui um termo que está ligado à visão e à capacidade de compor ou pintar figuras que são coloridas, portanto quem não vê, não imagina. A continuidade do texto irá estender essa definição e se em um primeiro momento, como nos dizia o trecho acima citado, era impossível tecer qualquer analogia entre o que se passa na cabeça de um cego e na nossa, agora a própria Carta irá propor esse tipo de comparação:

Mas se a imaginação de um cego não é mais do que a faculdade de recordar e combinar sensaçôes de pontos palpáveis, e a de um homem que vê, a faculdade de recordar e combinar pontos visíveis ou coloridos, segue-se que o cego de nascença percebe as coisas de uma forma muito mais abstrata que nós; e que, nas questôes de pura especulação, está talvez menos sujeito a enganar-se. (Diderot I979, p. Io)

O que então caracteriza a imaginação já não é mais a capacidade de recordar e combinar e figuras coloridas, mas sim a de recordar e combinar dados sensíveis em 
geral. De acordo com essa definição, o cego imagina, pois ele recorda e combina elementos que o tato, a audição, o paladar, o olfato lhe oferecem. E seria a partir dessa capacidade de ordenar e bem dispor os sentidos de que dispõe que o cego poderia ir além deles e chegar a "perceber" objetos que os seus sentidos não lhe dariam diretamente. É o caso do cego de Puisaux que é capaz de ter uma ideia muito coerente do que vem a ser um espelho sem jamais ter visto um: "Discorre tão bem e de maneira tão justa acerca de tantas coisas que lhe são absolutamente desconhecidas que seu comércio tiraria muito da força a essa indução que todos nós fazemos, sem saber por quê, daquilo que se passa em nós para aquilo que se passa dentro dos outros." (Diderot 1979, p. 4) O que não se pode negar é que o cego de Puisaux fala com justeza e coerência sobre coisas que "desconhece", entendo aqui por desconhecimento a incapacidade de ter o órgão que diretamente nos daria a sensação do objeto a ser conhecido. Assim, posso dizer que conheço o espelho, pois o vejo, e o cego o desconhece, pois não o vê. Mas se dele o cego pode ter uma noção exata (no mínimo tão exata como a que tenho), posso ainda dizer que ele desconhece o espelho? O que dizer, por exemplo, de Saunderson que "professou as matemáticas na universidade de Cambridge com um êxito espantoso. Deu liçôes de óptica; pronunciou discursos sobre a natureza da luz e das cores; explicou a teoria da visão; tratou dos efeitos das lentes, dos fenômenos do arco-íris e de várias matérias relativas à vista e a seu órgão"? (Diderot 1979, p. I5) A questão já não é mais a de saber se cegos como o de Puisaux ou Saunderson conhecem ou não esses objetos dos quais falam com propriedade, mas dos quais nunca tiveram uma visão, e sim o de entender como eles chegam a perceber ou ter noção de algo que seus sentidos não lhes oferecem nenhum dado direto. Em outros termos: que órgão é esse que nos permite sentir ou pensar o que, em um primeiro momento, nos seria impossível perceber? Responder a essa pergunta é tentar entender como o cego de Puisaux pôde ter a noção de espelho. O texto da Carta nos dirá que é "pelo relato dos outros homens" que ele pode ascender a percepção de algo que não perceberia imediatamente (Diderot 1979, p. 4). Ou seja: é graças ao entendimento do que os outros homens lhe dizem que o cego de Puisaux pode imaginar, a partir dos elementos que os seus sentidos the fornecem, algo que escapa à apreensão deles. Desse ponto de vista, a imaginação daria a possibilidade de sentir algo de modo indireto, em um tipo de atividade que, quando bem feita, seria capaz de suprir as deficiências de nossos sentidos. Graças a essa atividade, o cego pode "ver" e mesmo que sua visão seja uma visão imaginária, ela lhe torna capaz de se expressar bem acerca de objetos coloridos ou visíveis ao ponto de serem capazes de ministrarem aulas sobre ótica. Pelo mesmo tipo de atividade, seríamos capazes de compreender a coerência da fala 
de um cego. A imaginação ganharia assim um papel importante na comunicação e relação entre os homens na medida em que por ela podemos nos colocar no lugar dos outros e sentir (mesmo que aproximada e imaginariamente) o que eles sentem e pensam. Em um texto de 1758 , Discurso sobre a poesia dramática, ao comentar a importância da capacidade de imaginar, Diderot dirá que ela é "qualidade sem a qual não se pode ser nem um poeta, nem filósofo, nem homem de espírito, nem ser racional, nem homem". (Diderot 1986, p. 65) Algumas linhas adiante, ele acrescentará: "A imaginação é a faculdade de recordar imagens. Um homem completamente privado desta faculdade seria um estúpido, cujas funções intelectuais se reduziriam a produzir sons que aprendera a combinar na infância, aplicando-os maquinalmente às circunstâncias da vida". (Diderot 1986, p. 65) Um homem que não imagina, não comunica, e se ainda pode produzir algum som, estes terão de ser tomados como algo desarticulado, feito mecanicamente, tal como a fala de um papagaio. $\mathrm{Na}$ Carta, essa capacidade de se comunicar com eficácia e de se fazer bem entendido, malgrado todas as diferenças que separam as ideias e sensações dos homens, pode ser detectada pelo que aqui se denomina "expressōes felizes":

Os que escreveram sua vida (a de Saunderson) dizem que ele era fecundo em expressōes felizes. Mas o que entendeis por expressões felizes?, me perguntais quiçá. Eu vos responderei, senhora, que são aquelas que são próprias a um sentido, ao tato, por exemplo, e que são metafóricas ao mesmo tempo a um outro sentido, como aos olhos; daí resulta dupla luz para aquele a quem se fala, a luz verídica e direta da expressão, e a luz reflexa da metáfora. (Diderot 1979, p. I5)

É assim que o cego pode se expressar, pois é capaz de elaborar uma linguagem metafórica ou imaginária que, indo além dos dados diretos que seus sentidos lhe fornecem, atinge o restante dos homens. É assim que podemos entender o discurso do cego, pois somos capazes de compreender a metáfora que seu discurso de origem táctil pode nos oferecer. Se, como dissemos, o cego é apenas uma imagem amplificada das diferenças que separam cada um dos homens e os tornam seres singulares, percebendo um mundo que lhe é próprio e privado, a possibilidade da comunicação entre ele só pode ser vislumbrada quando se postula esse uso metafórico do discurso. Desse ponto de vista, ter bom senso é ser capaz de ir além do que nossos sentidos nos dão imediatamente e ascender a uma dimensão comum que nos retira da mera particularidade que nos tornaria idiotas ou seres ensimesmados. Como o bom ator que, segundo o Paradoxo sobre o comediante, tem de ser frio e afastar-se de suas próprias paixões e sentimento para ser capaz 
de representar os mais diversos tipos e personagens, o homem aqui precisaria ir além de si mesmo ou daquilo que os seus sentidos the daria originalmente para poder entrar em contato com os demais e tornar-se sociável. "Quantos gorjeios (ramage) diversos, quantos gritos dissonantes na mesma floresta que se chama sociedade!”, diz-nos a Satyre première (Diderot 1984, p. 584). ${ }^{2}$ E, no entanto, é dessas diferenças ou do desenvolvimento que delas se faz com bom senso que a sociabilidade e a ideia de uma comunidade se apresentam. Embora esse âmbito universal e comum tenha de ser pensado como sendo ideal, metafórico ou imaginário, é a partir dele ou nele que podemos vislumbrar a possibilidade de uma interlocução, de uma correspondência ou diálogo. O final da Carta, no próprio modo como relativiza as opiniōes por ela mesma apresentada, parece-nos significativo a esse respeito: "nós não sabemos portanto quase nada; entretanto, quantos escritos cujos autores pretenderam saber algo! Não chego a adivinhar por que o mundo não se enfastia de ler e de nada aprender, a menos que seja pela mesma razão pela qual há duas horas tenho a honra de vos entreter, sem me enfastiar e sem nada vos dizer." (Diderot I979, p. 29)

O que diz essa Carta? O que quer ela comunicar? Talvez nada ou quase nada, como não deixa de afirmar Diderot na última linha desse texto. E é justamente aí, na possibilidade de nada dizer, de saber que ainda é preciso dizer quando nada se diz, de poder soar tão estranha a nós quanto nossos discursos podem parecer estranhos a um cego ou a um surdo, que a Carta nos chama a atenção para aquilo que talvez seja um de seus conteúdos mais latentes e, ao mesmo tempo, o mais manifesto em sua forma de exposição: o fato de ser uma lettre e que, como tal, é ela mesma a prova de que a interlocução humana será correspondida quando feita com bom senso.

\section{Referências bibliográficas}

Alembert, J. "Aveugle”. In: Encyclopédie, ou Dictionnaire raisonné des sciences, des arts et des métiers. Paris: I75I.

Belaval, Y. "Lettre sur les aveugles à l'usage de ceux qui voient". In: Études sur Diderot. Paris: PUF, 2003.

Diderot, D. Carta sobre os cegos para o uso dos que veem. Tradução de J. Guinsburg. Col. Pensadores. São Paulo: Abril Cultural, 1979.

Lettre sur les aveugles à l'usage de ceux qui voient. Edição de André Billy. Paris: Gallimard, 195I.

2 Ver o comentário de Jean Starobinski a respeito dessa frase (Starobinski 20I2). 
. Addition à la Lettre precedente (addition à la Lettre sur les aveugles). Paris: Gallimard, 1951.

"Satyre première sur les caractères et les mots de caractère, de profession, etc". In: Diderot-oeuvres. Tomo II. Paris: Robert Laffont, 1994.

. "Belo". Tradução de Maria das Graças de Souza. In: Diderot, D.; D’Alembert, J. Enciclopédia, ou Dicionário razoado das ciências, das artes e dos oficios. Org. Pedro Paulo Pimenta e Maria das Graças de Souza. São Paulo: Unesp, 20I5.

Discurso sobre a poesia dramática. Tradução, apresentação e notas de L. F. Flanklin de Matos. São Paulo: Brasiliense, 1986.

Franklin de Matos, L. F. "As vinte bocas da sensação”. In: O filósofo e o comediante. São Paulo/ Belo Horizonte: Humanitas/Editora da UFMG, 200I.

Starobinski, J. Diderot, un diable de ramage. Paris: Gallimard, $20 \mathrm{I} 2$. 